\title{
Chemically Collapsible Mandrel for Solid Rocket Motor Processing
}

\author{
Abhijit Dey', Arvind Kumar, Arun K Sikder, Manoj Gupta
}

\begin{abstract}
Composite propellant mainly consists of two parts, binder matrix (prepolymer, plasticizer, cross linker, antioxidant and curative etc.) and solid ingredients (oxidizer, metal fuel, burn rate modifier, combustion stabilizer etc.). Its processing involves several stages like ingredient preparation (grinding, 1.1 Hazard Division - $1.1 \mathrm{HD}$ ), mixing (1.1 HD), casting (1.1 HD), curing (1.3 HD) and extraction (1.3 HD) Each and every process is very hazardous. Removal of any of the mentioned step will be a great achievement for solid rocket motor processing. Mandrel is used to give proper grain geometry. But for metal mandrel, its extraction process (1.3 HD) is very dangerous. Proper safety precaution should be taken to perform the said operation. Also, for a metal mandrel, it is very difficult to develop intricate grain geometry due to extraction problem. This paper mainly deals with casting techniques of propellants (case bonded or cartridge loaded) with a chemically collapsible mandrel. This mandrel is collapsed in presence of suitable chemicals, hence extraction step (1.3 HD) becomes simpler. As the extraction process is very easy, intricate grain geometry can be developed in solid rocket motor. The mandrel is cheap, recycleable and relatively lightweight compared to the metal mandrel, thus handling becomes very easy. The mandrel material and the dissolution solvent have no effect on the propellant, which will be confirmed by evaluation of physicochemical as well as ballistic properties measurement.
\end{abstract}

KEYWORDS: Mandrel, Grain geometry, Composite propellant, Extraction, Mould.

\section{INTRODUCTION}

Conventional composite propellants comprise solid oxidizer (ammonium perchlorate, ammonium nitrate, potassium perchlorate etc.), metal fuel (aluminum powder, zirconium powder) and binders (hydroxyl/carboxyl terminated poly butadiene pre-polymer with isocyanate based curator), which also act as a fuel and contain high ratio of oxidizers.

An increased amount of the solid loading in the propellant composition results in an increase in the viscosity of slurry (a fluid mixture of binder, oxidizer, metallic fuel etc.), which causes difficulty in the processing of propellant.

There are various methods of casting, but generally propellant slurry is cast by "vacuum gravity method" (top casting) (Davenas 1993; Krishnan et al. 1998), in an insulated motor cases or moulds. This technique is employed for casting large diameter rocket motors with large annular space or for slurries with low viscosities. Mandrel of required shape is positioned in the motor case or mould concentrically, and the slurry stored in feed hopper over casting chamber flows in the annular space (web) between mandrel and motor case under the influence of pressure differential (due to vacuum in casting chamber) and gravity. In "building block technique" (Krishnan et al. 1998), grain configuration is divided into multiple blocks, and suitably configured propellant blocks are separately cast and cured. Then, they are laid in the motor case and bonded using thin uncured propellant of the same composition. With the help of this technique, repairing and rework of larger built grain are also feasible. In bayonet casting method (Davenas 1993; Krishnan et al. 1998; Morgan and Dye 1989), bayonets are used to pump the slurry in the mould by air or nitrogen. The slurry will be de-aerated in the mixing phase itself and gradually pumped 
into the mould. As the level rises in the mould, the bayonet is withdrawn automatically. An improvement of bayonet casting has been suggested in US patent no 4,836,961 (Morgan and Dye 1989), in which the exit of bayonet consists of annular slit, which improves fluidity and self leveling behavior of the propellant slurry and thus helps in deaeration. In centrifugal casting technique, the slurry is introduced under pressure into the motor, which is kept spinning. As the propellant falls at the centre of the motor, the centrifugal force pushes the propellant towards the wall, de-aerating it. This method is suitable for making cylindrical port geometry motors. It has limitation on the size of job that can be handled and the requirement of machine for its rotation. Barometric leg casting method is the combination of pressure and vacuum casting. The propellant slurry is fed by pressure from the can through a slit plate and falls into a de-aeration assembly. The propellant is collected in this zone and pressure rises, and, once it is beyond the atmospheric pressure, it flows through the automatic valve into the mould. Propellant casting in motor cases with low annular space and slurries of high viscosities has been described employing another technique in which slurry is pressurized into the casting moulds from the bottom. This technique is called pressure casting/die casting.

A new casting method have been suggested in US patent 6,101,948(A) (Knaresboro et al. 2000) for manufacturing solid rocket motor. In this method, a mandrel consisting of at least one collapsible solid slot former is positioned centrally along the axis of rocket motor and propellant slurry is cast around the mandrel and collapsible solid slot former. Now, after curing of the solid propellant, the mandrel is removed, and the propellant and slot former is pressurized, causing the slot former to collapse as well as the easy removal from the cured propellant.

A novel construction of collapsible mandrel is described by Lembit et al. (2001). According to the invention, the outer wall comprises a plurality of sections with mating edge surfaces that diverge inwardly on odd-numbered sections and convergently on the alternating even-numbered sections of the mandrel wall, so that the odd-numbered set of sections may be retracted by a predetermined first amount instead of an even-numbered wall sections by a predetermined, lesser second amount. The collapsible mandrel is useful in a number of applications, such as the production of filament wound containers. In a particular embodiment of the invention, the retractible sections make up the walls of a vertically-oriented cylindrical retractible mandrel which may be used for fabricating large-diameter chimney liners of fibre-reinforced plastic.
According to US patent 3,237,913, the collapsible mandrel (Sellers and Brunswick 1966) is adopted for use in forming the cavity configuration in the solid propellant which is cast in large propulsion systems. As the propellant system increases, the weight of the mandrel will be necessarily increased in proportion to the size of the propulsion system. Thus, it becomes necessary to provide a mandrel, so that such a mandrel can be easily removed after propellant has cured without damage to the cavity configuration in the propellant. Such a mandrel could be easily assembled under controlled conditions and disassembled as found to be necessary and easily shipped to any location for reassembly and reuse on repeated occasions.

A reusuable cylindrically shaped, pivotally collapsible, foam mandrel used for manufacture of hollow impregnated fibre tubes was described in US patent 3,988,103 (Hoffmeister 1976). The mandrel includes a substantially rigid foam cylindrical member, an extractable member for aiding in collapsing the cylindrical member, such as groove. In one embodiment, a hinge member is employed to further aid in the pivotal collapsibility of the foam cylindrical member.

According to a special type of mandrel described in US patent 4,233,020 (Leo 1980), the mandrel has a cantilever-type mounting and includes a rotatable longitudinally slit tubular steel shell providing a molding surface on which thermosetting resin and glass fiber reinforcing material may be deposited to form tank bodies or pipe. A row of pneumatic actuators mounted inside the shell and spaced axially thereof includes piston rods attached to the shell along the slit on one side thereof. Retraction of the piston rods collapses the shell, which is flexible over the greater portion of its periphery and supported in the flexible portion by a plurality of rows of pivotable turnbuckle connectors or support rods, for removal of a cured tank body or pipe.

A collapsible mandrel (Pistole et al. 1981) having a longitudinally slit tubular shell providing a molding surface for glass fiber reinforced plastic pipe is provided with a removably mountable longitudinally slit sleeve as a molding surface for pipe of larger diameter.

A method of constructing a collapsible mandrel for use in fabricating filament wound vessels or tanks has been reported in US patent 4,684,423 (Brooks 1987). It includes the steps of preparing a rigid mandrel and supporting the mandrel on a rotatable axle, applying one or more layers of strips of rubber longitudinally on the mandrel to form an enclosure, applying coats of rubber solution over the layers, winding a layer of fibers over at least one of the layers, and curing the 
rubber layers. The layers are cut into two parts, removed from the rigid mandrel, and rejoined by using reinforcing straps along the seam of the joined parts. The collapsible mandrel may be used to fabricate either filament wound tanks or other collapsible mandrels, neither of which would have a seam or joint, since, after constructing the tank or second mandrel on the first inflated collapsible mandrel, the first mandrel would be deflated, collapsed and removed from the interior of the tank or second mandrel. This would leave a tank or second mandrel with continuous, unbroken layers forming the shell.

A propellant grain (Archer 2002) for a cylindrical casing has a cavity including an axially central opening with a combustion product exit port at one end. The grain bears a plurality of surfaces extending circumferentially about and disposed normally or helically to this opening so as to define, between these surfaces and axially toward the casing, alternating sections of propellant and sections of a groove or grooves in the propellant. The groove sections extend radially from the opening to a selectable distance to provide the grain with a large initial surface area while providing a high propellant volume.

Grain geometry is one of the important aspects in solid rocket propellant. Burning surface area depends on the grain geometry. As the grain geometry is getting more and more complex, it gives more and more burning surface area. But for scientists/technologists, the development of complex grain geometry in small motor is a challenge up to now. Extraction of metal mandrel is a 1.3 Hazard Division (HD) operation. Mechanically collapsible mandrel is already reported in the patents but extraction of this mandrel becomes a very hazardous operation. Hence, there arises a need for a suitable technique to develop complex grain geometry by casting such viscous propellant slurry directly within the lined motor case to have uniform web thickness.

The advantage of the present research is that it is a very simple method for casting propellant grain in a bonded case as well as cartridge loaded grain with complex design. Propellant slurry of high viscosity can be effectively cast. The mandrel used for casting is less expensive and it is chemically collapsible, thus post-casting extraction process is removed. Another advantage is less manpower required for handling. Another advantage is that dissolved mandrel material can be reused to make a new mandrel.

\section{EXPERIMENTAL SECTION}

This technique is helpful for casting viscous propellant slurries (viscosity ranges from 2,000 to 20,000 P) by using chemi-cally collapsible mandrel. Composite propellant consists of two parts, i.e. binder and solid ingredient. The binder, which consists of hydroxy terminated polybutadiene (HTPB: OH value 40 - $50 \mathrm{mgg}^{-1}$ moisture $0.15 \%$, from Orion Chemicals), was cured with toluene diisocyanate (TDI: purity 99\%, RI 1.565 - 1.567 at $30^{\circ} \mathrm{C}$; from Bayer). Dioctyl adipate (DOA: saponification value $303 \pm 3$, moisture $0.5 \%$, from Subhash Chemicals) was used as a plasticizer to increase the processability. The mixture $(1: 2)$ of trimethylol propane $(\mathrm{OH}$ value 1,220 , moisture $0.5 \%$; purchased from Celanese) and butane-1,4-diol (OH value 1,220, RI $1.444 \pm 0.002$ at $30{ }^{\circ} \mathrm{C}$, moisture $0.5 \%$, purchased from Biaf) was used as an adduct in the composition. Two different sizes of ammonium perchlorate were used in the propellant formulations. The first one consisted of pure, research grade ammonium perchlorate (purity 99\%, density 1.95, from Tamil Nadu Chlorates), with an average particle size of $300 \mu \mathrm{m}$. The other size of ammonium perchlorate was prepared by grinding ammonium perchlorate ( $>99 \%$ pure) in a fluid energy mill to an average particle size of $60 \mu \mathrm{m}$. Aluminum metal powder (from MEPCO) of an average particle size of $15 \mu \mathrm{m}$ was used as a metal fuel. The detail formulation has given in Table 1. The propellant is processed by mixing the ingredient in vertical planetary mixer.

The propellant formulations were mixed in $10 \mathrm{~kg}$ batches using a vertical planetary mixer of $15 \mathrm{~L}$ capacity. During mixing, vacuum ( 2 - 3 Torr) was applied at $55^{\circ} \mathrm{C}$, in order to remove air bubbles

Table 1. Propellant composition.

\begin{tabular}{|c|c|c|}
\hline Serial No. & Ingredients & Weight [\%] \\
\hline 1 & Hydroxy terminated polybutadiene (HTPB) & 10.4 \\
\hline 2 & Dioctyl adipate (DOA) & 3.8 \\
\hline 3 & Adduct: n-butanediol: Trimethylolpropane (2:1) & 0.12 \\
\hline 4 & Toluene diisocyanate (TDI) & 0.68 \\
\hline 6 & Ammonium perchlorate (AP) & 68 \\
\hline 7 & Aluminum (Al) & 17 \\
\hline
\end{tabular}


from the formulation prior to casting. The propellant mixture was cast under vacuum by slurry cast techniques. The propellant was cured at $60{ }^{\circ} \mathrm{C}$ for $10-12$ days in a water-jacketed oven.

The propellant formulations were subjected to various performance tests. The detailed flow chart for processing bonded case and cartridge loaded grain is presented in Figs. 1 and 2 .

In the present research, a chemically collapsible mandrel was designed and made up indigenously by styrofoam material with a metal core. Metal core is used to give proper load support and offset the bouncy force generated during propellant casting. The mandrel is specifically designed according to the requirement of casting. To avoid the reaction between mandrel material, propellant and dissolution liquid, coating with wax material has been carried out over the mandrel. This coating is removed very easily after curing.

\section{BRIEF DESCRIPTION OF THE PROCESS}

It is understood that, while the study has been described in conjunction with preferred specific embodiments thereof, Figs. 3-7 intend to illustrate and not limit the scope of the study. Other aspects, advantages and modifications within the scope of the study will be apparent to those skilled in the art to which the study pertains, following casting arrangements and process.

\section{Vacuum Casting Chamber}

It is a pressure vessel designed to withstand full vacuum. The purpose of this chamber is to deaerate the slurry during casting. An absolute pressure of $4-6 \mathrm{mmHg}$ is maintained in the chamber throughout the deaerating process.

\section{Propellant Feeder}

It is basically a feeding hopper made up of stainless steel. At the bottom of the hopper, a ball valve is fitted to control the flow of the propellant.

\section{Base Plate}

It is a specially designed bottom plate to fit the base of the motor and held the mandrel from one end.

\section{Mandrel}

The mandrel is specifically designed according to the requirement of casting. In the present study, the mandrel is basically made up

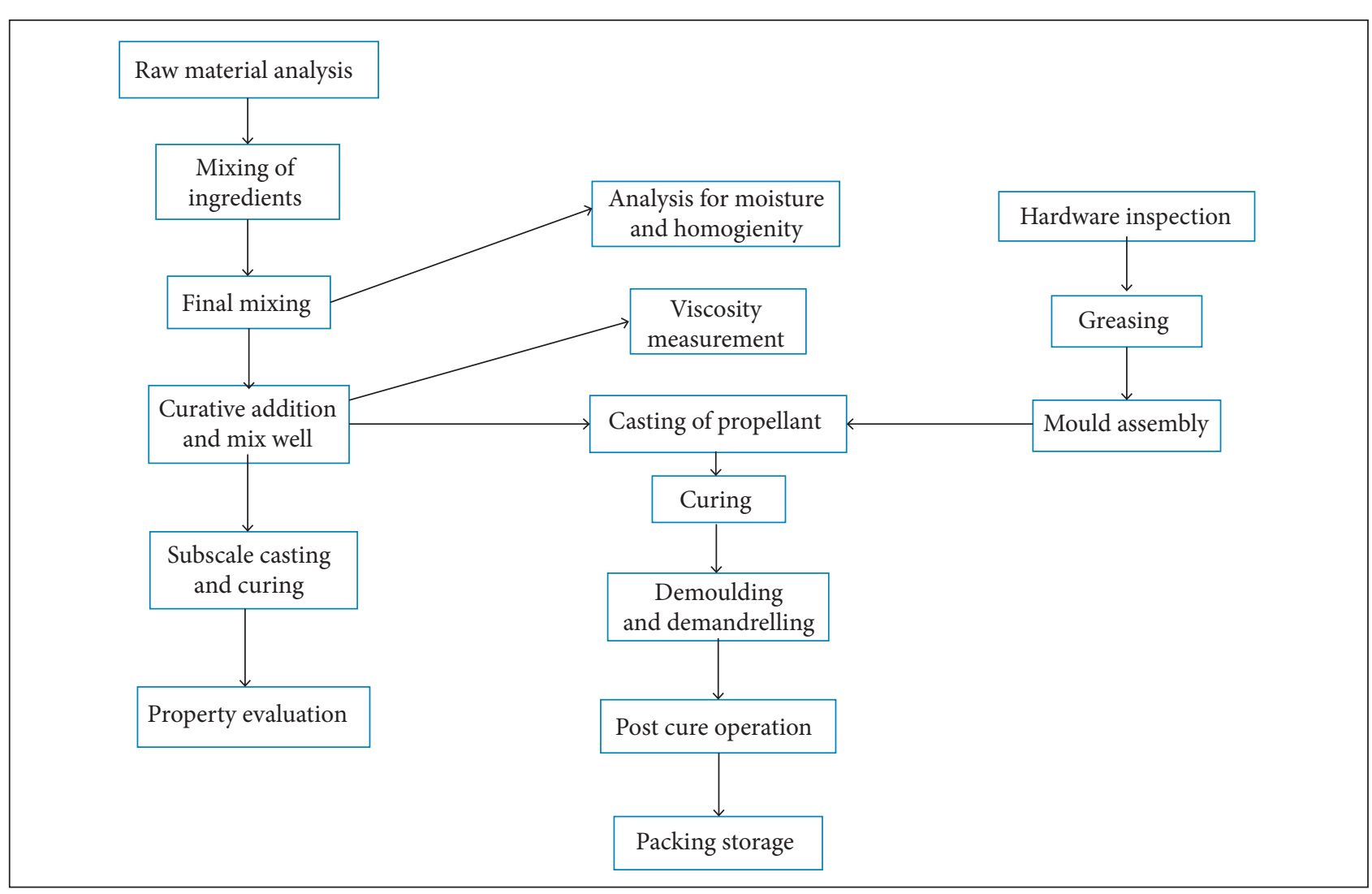

Figure 1. Process flow chart for cartridge loaded grain. 
of indigenously made styrofoam material with a metal core. A wax coating is also applied over the assembly to protect the styrofoam from propellant ingredient during the curing. A metal core is used to give load support. This mandrel is fitted in place of an actual metal mandrel. Fig. 3(a) shows a collapsible mandrel with metal core and styrofoam sheet. Fig. 3(b) shows a propellant grain after curing. The hollow part is created by the mandrel. Fig. 3(c) depicts the complete casting mould with a specially designed mandrel. Figures 4-6 exhibit the pictorial representation of the mandrel (Fig. 4), its cross-sectional view (Fig. 5) and the casting mould with collapsible mandrel after casting (Fig. 6).

\section{Preparation of Propellant Slurry}

Propellant slurry is prepared by mixing powder ingredients in pre-polymer resin. After the completion of the mixing cycle, homogeneity and slurry moisture of the mixed sample are checked. Later on a curative is added after ensuring the readiness of the casting assembly. The composition must meet ballistic and mechanical properties. The viscosity of the slurry is generally between 5,000 to $8,000 \mathrm{P}$ and built-up viscosity after 3 hours may reach up to 12,000 P. From the mixer, the propellant slurry is unloaded into a slurry hopper for further operations.

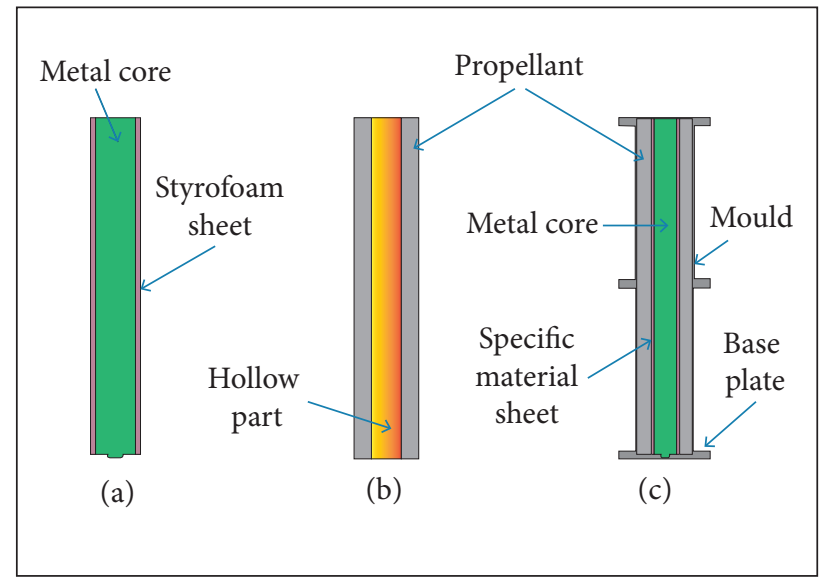

Figure 3. (a) Collapsible mandrel, (b) Propellant grain and (c) Casting mould with mandrel.

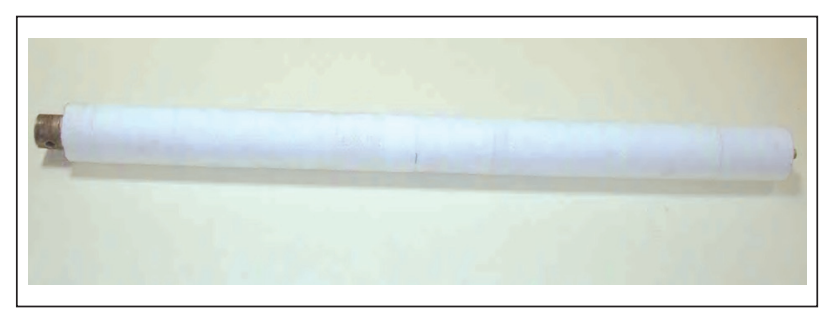

Figure 4. Chemically collapsible mandrel with a metal core.

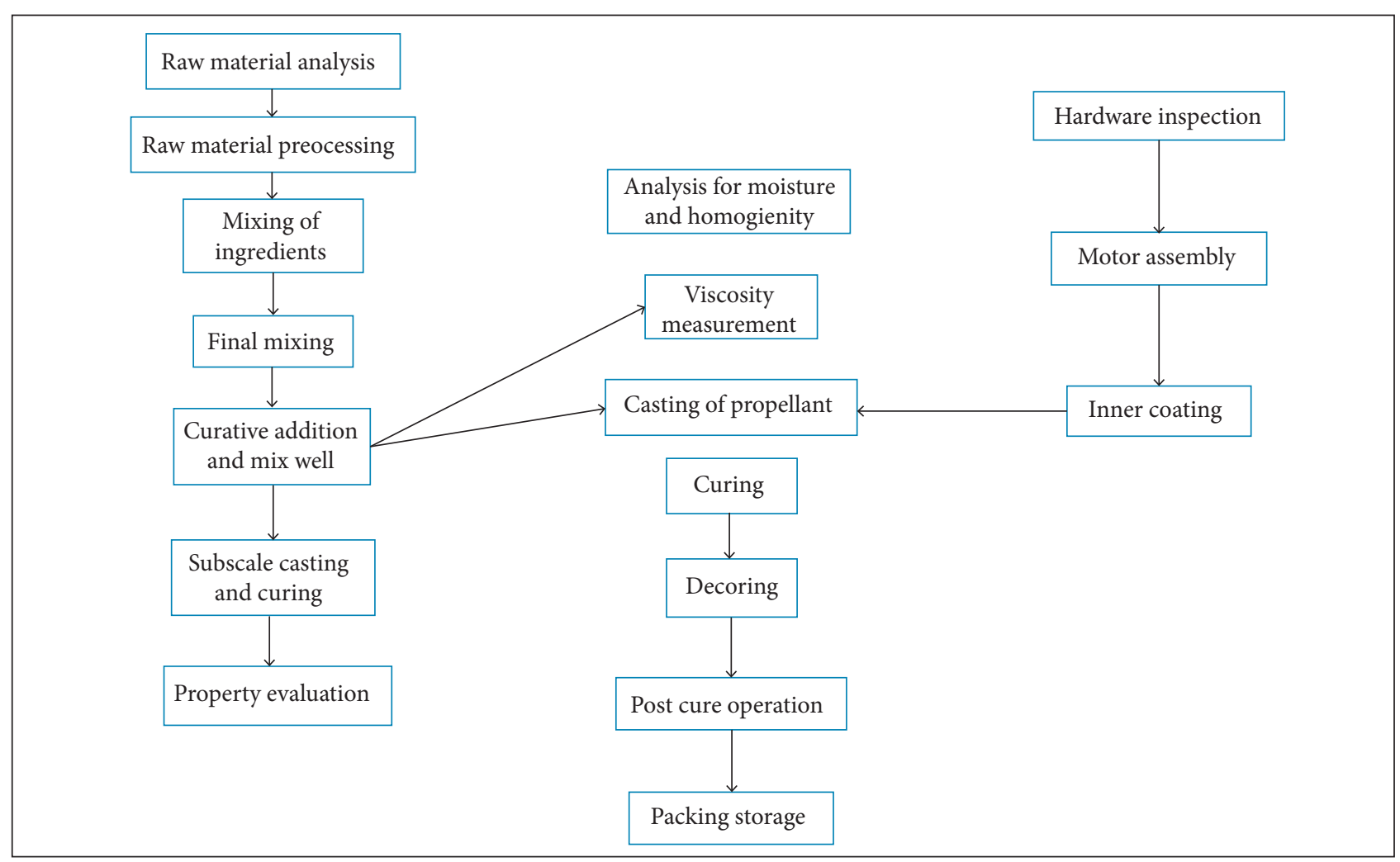

Figure 2. Process flow chart for cartridge loaded grain. 


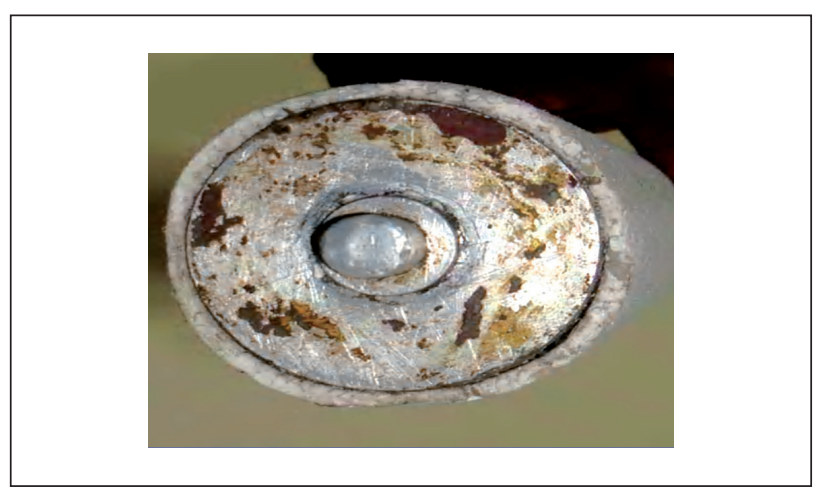

Figure 5. Cross-sectional view of collapsible mandrel with metal core.

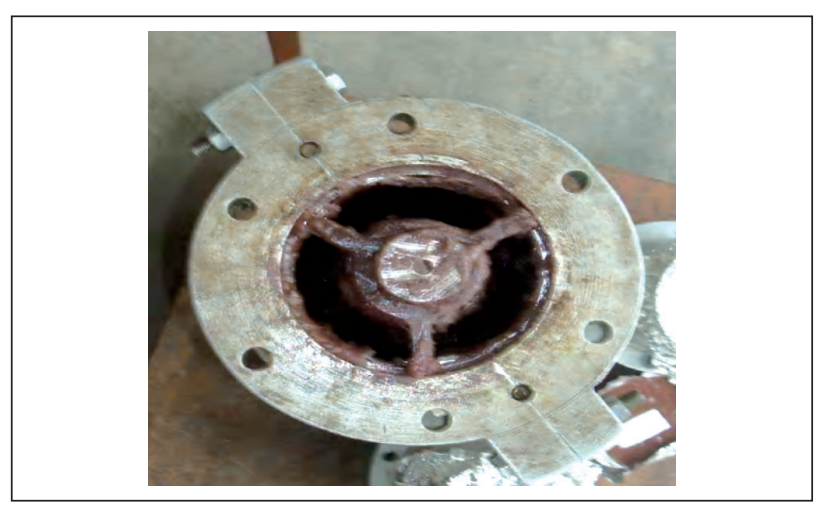

Figure 6. Casting mould with collapsible mandrel after casting.

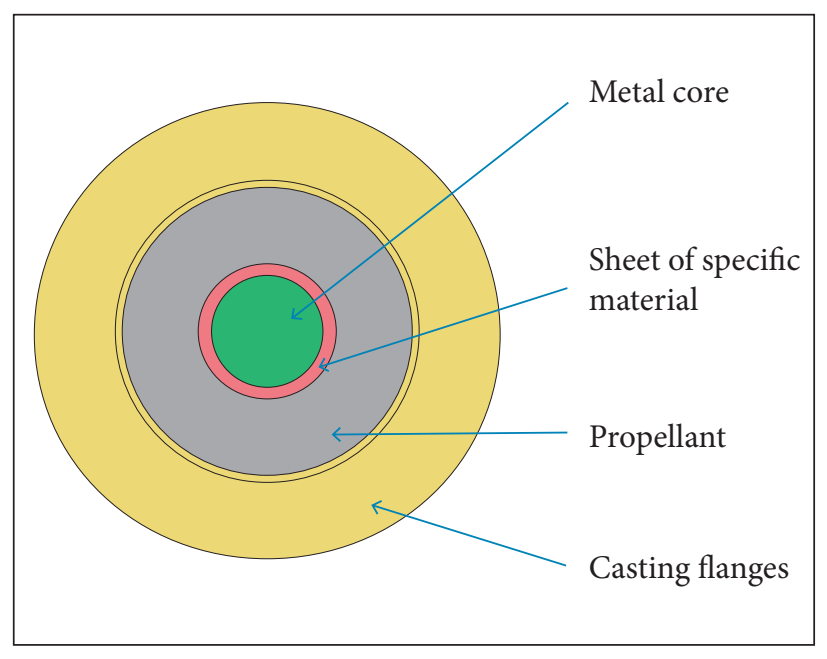

Figure 7. Cross-sectional view of casting assembly with mandrel.

\section{Casting Process}

Vacuum is applied in the vacuum casting chamber through oil ring vacuum pump till the absolute pressure inside the chamber reaches $3-4 \mathrm{mmHg}$. This pressure inside the casting chamber is maintained throughout the deaeration process.
Propellant slurry is fed into the feed hopper, which is placed over the vacuum casting chamber through feed valve. Then, the feed valve below the slurry hopper is slowly opened to allow the propellant slurry to flow inside the motor. The flow of slurry inside the motor is maintained at a rate of approximately $400-600 \mathrm{~g} / \mathrm{min}$. Slurry through the valve falls directly inside the motor, which allows large slurry surface area for deaeration. Slurry level in the motor kept inside the casting chamber is monitored through the viewing port. When the required amount of propellant flows inside the motor, the feed valve is closed and the motor along with the mandrel and the slurry mix is kept under vacuum for $30 \mathrm{~min}$. Then, the vacuum is released and the lid of the vacuum casting chamber is removed.

\section{Propellant Curing and Post-Cure Operations}

After casting, the motor is kept in a curing oven at appropriate temperature and for the required period for curing the propellant. When the propellant curing is completed, the oven is switched off and the motor is slowly allowed to cool down to the ambient temperature. Two types of casting mould were assembled: one with regular mandrel and other with chemically collapsible mandrel to compare propellant physicochemical properties and ballistic properties. Extraction of regular mandrel was carried out by regular practice. But, in case of chemically collapsible mandrel, the propellant containing casting mould was placed vertically and a dissolution solvent (ketonic solvent) was applied over the material. When the chemical solution touches the material, it dissolves entirely and the metal core is removed easily. Other casting accessories are removed and the excess of propellant is trimmed off. Figure 7 represents the cross-sectional view of the casting assembly with mandrel.

\section{CHARACTERIZATION}

All the physicochemical and ballistic properties have been evaluated for comparison. Strand burning rates of the propellants were determined in the pressure range of $5-9 \mathrm{MPa}$ by employing an Acoustic Emission Technique (Christensen 1978). The methodology involved combustion of the strand (ignited by means of a nichrome wire) with dimensions of $100 \mathrm{~mm} \times 6 \mathrm{~mm} \times 6 \mathrm{~mm}$ in the nitrogen pressurized steel bomb. The acoustic signal generated and the perturbations caused by the propellant deflagration were transmitted through the water medium to a piezoelectric transducer $(200 \mathrm{kHz})$ in conjunction with an oscilloscope. The burning rates were computed from the time they were recorded for the trial conducted at each 
pressure for each sample. The standard deviation was of the order of $0.2 \%$.

Calorimetric values were obtained using a bomb calorimeter (Parr instruments, Germany). The density of the propellants was determined by a Metler density kit. Toluene was used as a solvent.

Density $=\frac{\left[\begin{array}{l}\text { weight of } \\ \text { the sample }\end{array}\right]}{\left[\begin{array}{c}\text { weight of the } \\ \text { sample in solvent }\end{array}\right]} \times\left[\begin{array}{l}\text { specific gravity } \\ \text { of the solvent }\end{array}\right]$

The sensitivity to impact the stimuli of the propellant compositions was determined with a fall hammer apparatus (2 kg drop weight) using the Bruceton Staircase method (Brooks 1987), and the results were given in terms of the statistically obtained $50 \%$ probability of explosion (H50). The friction sensitivity was measured on a Julius Peter apparatus by incrementally increasing the load from 0.2 to $36 \mathrm{~kg}$, until there was ignition/explosion in 5 consecutive test samples.

The ignition temperatures were measured by a Julius Peters apparatus. The sample was heated uniformly at a constant rate $\left(5^{\circ} \mathrm{C} / \mathrm{min}\right)$ in a Woods metal bath, until it exploded or ignited at the ignition temperature.

Thermal analysis of the propellant was carried out on the STA (Q-600,USA), Perkin Elmer Pyris Diamond DSC, at the heating rate of $20^{\circ} \mathrm{C} / \mathrm{min}$ under $\mathrm{N}_{2}$ atmosphere (sample mass of $\sim 10 \mathrm{mg}$ ). Gaseous decomposition products were analyzed by Bruker make equinox 55 hyphenated with TG.

Mechanical properties were obtained with Instron (Model TIC-1185, UK). The operating instrumental parameters were always maintained constant - gauge length: $25 \mathrm{~mm}$; crosshead speed: $50 \mathrm{~mm} / \mathrm{min}$. The stress and strain properties were determined using dumbbell shaped specimen as per specification ASTM-D-638.

\section{RESULTS}

During this operation, no increase in temperature was observed. It became very easy to remove the metal core. The outer diameter and the inner one were measured, and no deformation was found. There were various sample pieces like dumbbells and density pieces. Strends and $2 \mathrm{~kg}$ of ballistic evaluation motor (BEM) were cut from the grain. No change in ballistic and physical properties was observed. The detail results are given next.

Table 2 shows the data of viscosity, density and calorimetric value with standard deviation which have been prepared with a metal mandrel and a chemically collapsible one. The experimental results show marginal variation.

According to Table 3, friction, impact and ignition temperature data with standard deviation have been highlighted. The experimental data were found to be an acceptable range in both experiments.

Mechanical properties data were highlighted in Table 4. According to this table, the mechanical properties also showed consistent results for both grains. Experimental results showed that propellant mechanical properties are not affected by the dissolution solvent, which was used for mandrel dissolution.

Tables 5 and 6 represent thermal and ballistic analyses results with standard deviation. No change in the properties was observed. We also conclude that chemically collapsible mandrel material and its dissolution solvent do not affect the propellant's thermal and ballistic properties. Specially, burn rate data for both propellant grains found an excellent match.

Table 2. Physicochemical properties of propellant composition.

\begin{tabular}{c|c|c|c|c|c|}
\multirow{2}{*}{ Composition } & Viscosity (Poise) & \multicolumn{2}{|c|}{ Density [g/cc] } & \multicolumn{2}{c|}{ Calorimetric value [cal/g] } \\
\cline { 2 - 7 } & Initial & $\begin{array}{c}\text { With metal } \\
\text { mandrel }\end{array}$ & $\begin{array}{c}\text { With chemically } \\
\text { collapsible mandrel }\end{array}$ & $\begin{array}{c}\text { With metal } \\
\text { mandrel }\end{array}$ & $\begin{array}{c}\text { With chemically } \\
\text { collapsible mandrel }\end{array}$ \\
\hline CP-1 & $5,440 \pm 100(44.3)$ & $1.748 \pm 0.01$ & $1.748 \pm 0.01$ & $1,882 \pm 10$ & $1,886 \pm 10$ \\
\hline
\end{tabular}

Table 3. Sensitivity data.

\begin{tabular}{c|c|c|c|c|c|c|} 
& \multicolumn{4}{|c|}{ Sensitivity parameter } & \multicolumn{2}{c|}{ Ignition temperature ( $^{\circ} \mathrm{C}$ ) } \\
\cline { 2 - 7 } Composition & $\begin{array}{c}\text { With metal } \\
\text { mandrel }\end{array}$ & $\begin{array}{c}\text { With chemically } \\
\text { collapsible } \\
\text { mandrel }\end{array}$ & $\begin{array}{c}\text { With metal } \\
\text { mandrel }\end{array}$ & $\begin{array}{c}\text { With chemically } \\
\text { collapsible mandrel }\end{array}$ & $\begin{array}{c}\text { With metal } \\
\text { mandrel }\end{array}$ & $\begin{array}{c}\text { With chemically } \\
\text { collapsible mandrel }\end{array}$ \\
\cline { 2 - 8 } CP-1 & $144 \pm 16$ & $144 \pm 16$ & $46.5 \pm 2$ & $47.0 \pm 2$ & $282.6 \pm 1$ & $282.2 \pm 1$
\end{tabular}


Table 4. Mechanical properties data.

\begin{tabular}{|c|c|c|c|c|c|c|}
\hline \multirow[b]{3}{*}{ Composition } & \multicolumn{6}{|c|}{ Mechanical properties } \\
\hline & \multicolumn{2}{|c|}{ Tensile strenght (maximun] $\left[\mathrm{kgf} / \mathrm{cm}^{2}\right.$ ] } & \multicolumn{2}{|c|}{$\%$ elongation } & \multicolumn{2}{|c|}{ E-Modulus (kgf/cm²] } \\
\hline & $\begin{array}{l}\text { With metal } \\
\text { mandrel }\end{array}$ & $\begin{array}{c}\text { With chemically } \\
\text { collapsible } \\
\text { mandrel }\end{array}$ & $\begin{array}{l}\text { With metal } \\
\text { mandrel }\end{array}$ & $\begin{array}{c}\text { With chemically } \\
\text { collapsible } \\
\text { mandrel }\end{array}$ & $\begin{array}{l}\text { With metal } \\
\text { mandrel }\end{array}$ & $\begin{array}{l}\text { With chemically } \\
\text { collapsible mandrel }\end{array}$ \\
\hline CP-1 & $10.5 \pm 2$ & $10.7 \pm 2$ & $43.7 \pm 10$ & $42.5 \pm 10$ & $44.6 \pm 5$ & $42.0 \pm 5$ \\
\hline
\end{tabular}

Table 5. Thermal analysis results of propellant composition.

\begin{tabular}{|c|c|c|c|c|c|c|c|c|}
\hline \multirow[b]{2}{*}{ Composition } & \multicolumn{3}{|c|}{ DSC@10 @ C/min } & \multicolumn{3}{|c|}{ DTA @ $20^{\circ} \mathrm{C} / \mathrm{min}$} & \multicolumn{2}{|c|}{ TGA@ $20^{\circ} \mathrm{C} / \mathrm{min}$} \\
\hline & $\begin{array}{c}\text { Peak } \\
\text { temperature } \\
\left.{ }^{\circ} \mathrm{C}\right]\end{array}$ & $\Delta \mathrm{H}[\mathrm{J} / \mathrm{g}]$ & $\begin{array}{c}\text { Activation } \\
\text { energy } \\
\text { [kJ/M] }\end{array}$ & $\begin{array}{l}\text { Tinitial } \\
\left({ }^{\circ} \mathbf{C}\right]\end{array}$ & $\begin{array}{l}\text { Tmax } \\
{\left[{ }^{\circ} \mathrm{C}\right]}\end{array}$ & $\begin{array}{l}\text { Tfinal } \\
{\left[{ }^{\circ} \mathbf{C}\right]}\end{array}$ & $\begin{array}{c}\text { Temperature } \\
\left.\text { [ }{ }^{\circ} \mathrm{C}\right]\end{array}$ & $\begin{array}{l}\text { Weight } \\
\text { loss [\%] }\end{array}$ \\
\hline CP-1 & $400.7 \pm 5$ & $-1,671.4 \pm 10$ & $279.7 \pm 10$ & $242.9 \pm 2$ & $300.33 \pm 2$ & $371.0 \pm 2$ & $\begin{array}{l}249.4( \pm 5)- \\
416.1( \pm 5)\end{array}$ & $62.9 \pm 10$ \\
\hline
\end{tabular}

Table 6. Ballistic properties of propellant composition.

\begin{tabular}{|c|c|c|c|c|c|}
\hline \multirow{3}{*}{ Composition } & \multicolumn{5}{|c|}{ Ballistic properties } \\
\hline & \multicolumn{3}{|c|}{ Burn rate $[\mathrm{mm} / \mathrm{s}]$} & \multirow{2}{*}{$\begin{array}{c}n \text { value, } \\
5 \text { - } 10 \text { Mpa }\end{array}$} & \multirow{2}{*}{$\begin{array}{c}\text { a value } \\
5-10 \text { Mpa }\end{array}$} \\
\hline & 5 Мpa & $7 \mathrm{Mpa}$ & 10 Мpa & & \\
\hline $\mathrm{CP}-1$ & $6.68 \pm 0.5$ & $7.91 \pm 0.5$ & $9.47 \pm 0.5$ & $0.5 \pm 0.1$ & $0.931 \pm 0.1$ \\
\hline
\end{tabular}

\section{CONCLUSIONS}

It was concluded that all the important properties of propellants like viscosity, density, calorimetric value, friction, impact, ignition temperature, mechanical properties, thermal analysis and ballistic properties show marginal variation, which can be acceptable for our study. Several major advantages like removal of hazardous operation such as extraction $(1.3 \mathrm{HD})$, development of critical grain, room temperature, cost effective operation and less manpower involvement create the importance of this casting methodology.

\section{ACKNOWLEDGEMENTS}

The authors are thankful to Shri B. Bhattacharya, Director of High Energy Materials Research Laboratory, for valuable suggestions, constant encouragement and permission to publish this study.

\section{REFERENCES}

Archer HI, inventor; Propellant grain configuration. 2002 Aug 13. US 6,431,072 B1.

Brooks JC, inventor; Method fabricating a collapsible mandrel structure to be used in manufacturing reinforced hollow tanks. 1987 Aug 04. US 4,684,423.

Christiansen WN (1978) In: Proceedings of the 14th Joint Propulsion Conference on Ferrocene, American Institute of Aeronautics and Astronautics/Society of Automotive Engineers; Las Vegas, USA.

Davenas A (1993) Solid rocket propulsion technology. New York: Pergamon Press.

Hoffmeister AC, inventor; Collapsible mandrel for making fiber tubes. 1976 Oct 26. US 3,988,103.
Knaresboro DL, Goodson FR, Inman FS, inventors; Method of manufacturing solid rocket motors. 2000 Aug 15. US 6101948 (A).

Krishnan S, Chakravarthy SR, Athithan SK (1998) Propellant and explosives technology. New Delhi (India): Allied Publishers.

Lembit S, inventor; Collapsible mandrel. 2001 Aug 24. CA 2299487 A1.

Leo OA, inventor; Collapsible mandrel. 1980 Nov 11. US 4,233,020.

Morgan RE, Dye CB, inventors; Methods of and apparatus for casting solid propellant rocket motors. 1989 Jun 06. US 4,836,961(A).

Pistole RG, Stoll WA, Leo OA, inventors; Sleeve for changing diameter of collapsible mandrel. 1981 Jul 14. US 4,278,490.

Sellers HH, Brunswick GA, inventors; Collapsible mandrel for forming a cavity in solid rocket fuel. 1966 Mar 01. US 3,237,913. 